\title{
CORRESPONDÊNCIA
}

\section{Envolvimento do sistema nervoso central em pacientes chagásicos imunossuprimidos}

Recentemente, foi publicado nesta revista o artigo de Lazo et al. - Chagasic meningoencephalitis in the immunodeficient ${ }^{1}$. Os autores, baseados na experiência pessoal e nos dados da literatura, comparam as alterações neuropatológicas resultantes da reativação da infecção pelo Trypanosoma cruzi nos pacientes $\mathrm{HIV+,} \mathrm{com} \mathrm{aquelas} \mathrm{observadas} \mathrm{e} \mathrm{descritas} \mathrm{na} \mathrm{história} \mathrm{natural} \mathrm{da} \mathrm{doença} \mathrm{de} \mathrm{Chagas.} \mathrm{Embora} \mathrm{neste} \mathrm{artigo}$ os autores tenham detalhado os achados neuropatológicos nos pacientes chagásicos imunodeficientes, a distinção entre este quadro anatomopatológico e o encontrado nas fases aguda e crônica da doença de Chagas já havia sido relatada em trabalho anterior por Pittella² . De fato, neste trabalho de revisão do envolvimento do sistema nervoso central na doença de Chagas, o autor afirma que o envolvimento do encéfalo nos pacientes chagásicos imunossuprimidos, do ponto de vista neuropatológico, difere dos quadros até então conhecidos que ocorrem na fase aguda da doença, nos seguintes aspectos $\left.{ }^{2}: 1\right)$ encefalite necrosante em focos múltiplos; 2) presença da forma tumoral em alguns pacientes, caracterizada por lesões nodulares necrótico-hemorrágicas isoladas ou múltiplas, usualmente localizadas nos hemisférios cerebrais; 3) parasitismo intenso, numerosas amastigotas sendo sempre identificadas. Neste mesmo artigo de revisão Pittella ${ }^{2}$ propõe uma possível história natural do envolvimento do sistema nervoso central na doença de Chagas e afirma que a reativação da infecção no tecido nervoso em pacientes chagásicos crônicos é incomum e ocorre somente em indivíduos imunossuprimidos, observação esta também não referida pelos autores acima ao comentarem a reativação da infecção na doença de Chagas ${ }^{1}$.

\section{REFERÊNCIAS}

1. Lazo J, Meneses ACO, Rocha A, Ferreira MS, Marquez JO, Chapadeiro E, Lopes ER. Chagasic meningoencephalitis in the immunodeficient. Arq Neuropsiquiatr 1998;56:93-97.

2. Pittella JEH. Central nervous system involvement in Chagas'disease: an updating. Rev Inst Med Trop S. Paulo 1993;35:111-116.

José Eymard Homem Pittella

Laboratório de Neuropatologia Departamento de Anatomia Patológica e Medicina Legal Faculdade de Medicina da UFMG Av. Alfredo Balena 190, 30130-100 Belo Horizonte MG

\section{RESPOSTA DOS AUTORES}

Nosso artigo, publicado em Arquivos de Neuro-Psiquiatria 1998;56(1):93-97, é um trabalho de revisão baseado, como está claramente exposto, na experiência pessoal dos autores e em dados da literatura.

No tópico REFERENCES, a citação 22 corresponde ao artigo citado pelo Professor Pittella em sua Carta ao Editor.

Pelos autores,

Javier Lazo

Curso de Pós-Graduação em Patologia

Faculdade de Medicina do Triângulo Mineiro

Av. Getúlio Guaritá 130, 38025-440 Uberaba MG

CORRESPONDÊNCIA. Esta seção divulga opiniões e observações construtivas acerca de artigos publicados nos últimos números de Arquivos de Neuro-Psiquiatria. São aceitas cartas assinadas, sucintas e desprovidas de caráter pessoal, abordando aspectos objetivos dos artigos e utilizando até cinco referências bibliográficas. 